\title{
Melioidosis at Royal Darwin Hospital in the big 2009-2010 wet season: comparison with the preceding 20 years
}

Uma Parameswaran MB BS, Infectious Diseases Registrar

Robert W Baird MB BS, FRACP, FRCPA Director of Microbiology

Linda M Ward

BAppSci, MMedSci, Biostatistician/ Epidemiologist

Bart J Currie FRACP, FAFPHM, DTMTH, Infectious Diseases Physician,' and Program Leader

1 Royal Darwin Hospital, Darwin, NT.

2 Menzies School of Health Research, Darwin, NT.

bart.currie@ menzies.edu.au

MJA 2012; 196: 345-348 doi:10.5694/mjall.11170

Clinical focus p 322 Case report p 350

1 Melioidosis cases by year from 1 October 1989 to 30 September 2010

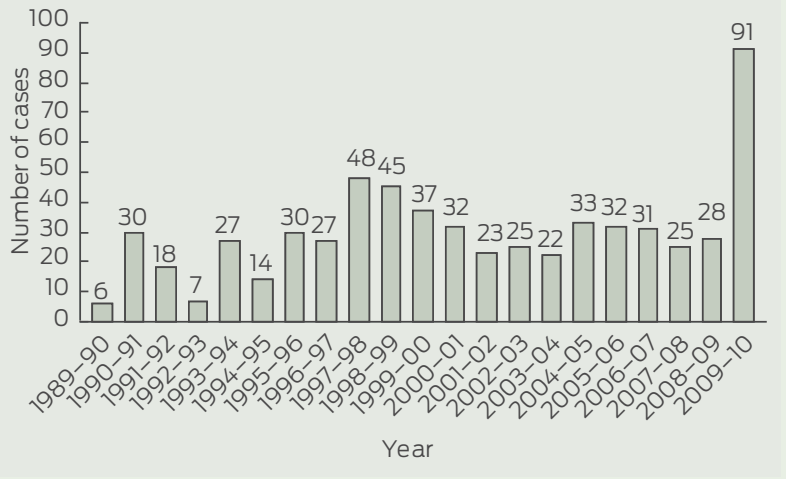

elioidosis is an infection caused by the soil and water bacterium Burkholderia pseudomallei, and was first documented in Australia in 1949 in Winton, Queensland, where sheep were infected. ${ }^{1}$ It was first reported in the Northern Territory in $1960 .^{2}$ Since then, melioidosis has been increasingly recognised as an important cause of sepsis in northern Australia, ${ }^{3-6}$ with the vast majority of cases occurring during the monsoonal rainy season during October to April.

The Darwin Prospective Melioidosis Study commenced on 1 October $1989 .{ }^{7}$ Over the 20 years until 30 September 2009, 540 culture-confirmed cases of melioidosis were documented from the Top End of the NT. ${ }^{6}$ This represented a median of 27 (range, 6-48) cases per year. From 1 October 2009 until 30 September 2010, an unprecedented 91 patients with culture-confirmed cases of melioidosis were managed by Royal Darwin Hospital (RDH). In this study, we compare these 91 cases from that most recent 12 -month period with the 540 cases from the preceding 20 years.

\section{Methods}

The Top End of the NT has an estimated population of 177500 people, with 124500 living in Darwin. ${ }^{8}$ Indi- 
2 Demographic characteristics and location of residence for patients with melioidosis managed at Royal Darwin Hospital from 1 October 1989 to 30 September 2010

\begin{tabular}{|c|c|c|c|c|}
\hline Demographic characteristics & 1989-2009 & 2009-2010 & Odds ratio $(95 \% \mathrm{Cl}) *$ & $P$ \\
\hline \multicolumn{5}{|l|}{ All patients } \\
\hline Number of cases & 540 & 91 & & \\
\hline Median number of cases/year & 27 & 91 & & $<0.001$ \\
\hline Median age (years) & 49 & 53 & & \\
\hline No. of children aged $<15$ years & $26(5 \%)$ & $3(3 \%)$ & & 0.71 \\
\hline Male & $372(69 \%)$ & $61(67 \%)$ & & 0.82 \\
\hline Indigenous & $281(52 \%)$ & $49(54 \%)$ & & 0.80 \\
\hline Darwin urban $^{\dagger}$ & $262(49 \%)$ & $59(65 \%)$ & $1.96(1.20-3.19)$ & 0.006 \\
\hline Indigenous & $99(38 \% \ddagger)$ & $31(53 \% \ddagger)$ & $1.82(0.99-3.35)$ & 0.05 \\
\hline Darwin rural ${ }^{\dagger}$ & $65(12 \%)$ & $12(13 \%)$ & & 0.89 \\
\hline Remote Indigenous communities & $169(31 \%)$ & $15(16 \%)$ & $0.43(0.23-0.80)$ & 0.006 \\
\hline Other ${ }^{5}$ & $44(8 \%)$ & $5(5 \%)$ & & 0.51 \\
\hline \multicolumn{5}{|l|}{ Indigenous patients } \\
\hline Number of cases & 281 & 49 & & \\
\hline Median age (years) & 45 & 49 & & \\
\hline Male & $169(60 \%)$ & $28(57 \%)$ & & 0.81 \\
\hline Darwin urban ${ }^{\dagger}$ & $99(35 \%)$ & 31 (63\%) & $3.17(1.62-6.24)$ & $<0.001$ \\
\hline Darwin rural $^{\dagger}$ & $8(3 \%)$ & 0 & & 0.49 \\
\hline Remote Indigenous communities & $153(54 \%)$ & $14(29 \%)$ & $0.34(0.16-0.68)$ & 0.001 \\
\hline Other ${ }^{5}$ & $21(7 \%)$ & $4(8 \%)$ & & 1.00 \\
\hline
\end{tabular}

* Odds ratios and $95 \%$ confidence intervals were calculated, comparing the odds of the parameter occurring in melioidosis cases in 2009-2010 versus 1989-2009. † See Methods for definitions. ₹Percentage of Darwin urban. $\$$ Including Katherine, Gove and central Australia.

3 Host risk factors and associated deaths for patients with melioidosis managed at Royal Darwin Hospital from 1 October 1989 to 30 September 2010

\begin{tabular}{lccccc} 
Risk factors & $1989-2009$ & $\mathbf{2 0 0 9 - 2 0 1 0}$ & $\boldsymbol{P}$ & $\begin{array}{c}\text { Deaths } \\
\text { 1989-2009* }\end{array}$ & $\begin{array}{c}\text { Deaths } \\
\text { 2009-2010* }\end{array}$ \\
\hline Total patients & 540 & 91 & & & \\
Diabetes & $213(39 \%)$ & $44(48 \%)$ & 0.14 & $33(15 \%)$ & $4(9 \%)$ \\
Hazardous alcohol intake & $211(39 \%)$ & $40(44 \%)$ & 0.45 & $33(16 \%)$ & $7(18 \%)$ \\
Chronic lung disease & $140(26 \%)$ & $26(29 \%)$ & 0.69 & $27(19 \%)$ & $5(19 \%)$ \\
Chronic renal disease & $65(12 \%)$ & $7(8 \%)$ & 0.30 & $13(20 \%)$ & $1(14 \%)$ \\
$\begin{array}{l}\text { Rheumatic heart disease and/or } \\
\text { cardiac failure }\end{array}$ & $39(7 \%)$ & $11(12 \%)$ & 0.17 & $9(23 \%)$ & $3(27 \%)$ \\
Malignancy & $31(6 \%)$ & $9(10 \%)$ & 0.20 & $8(26 \%)$ & $1(11 \%)$ \\
Immunosuppression & $31(6 \%)$ & $10(11 \%)$ & 0.10 & $6(19 \%)$ & $1(10 \%)$ \\
No host risk factor & $106(20 \%)$ & $16(18 \%)$ & 0.75 & $2(2 \%)$ & 0 \\
\hline * Percentage with risk factor who died. & & & & &
\end{tabular}

patients in 2009-2010 were similar to those of the 540 patients in 1989-2009 (Box 2, Box 3, Box 4). The proportion of patients acquiring melioidosis in the Darwin urban area increased significantly from $49 \%$ in 1989-2009 to $65 \%$ in $2009-2010$ (OR, 1.96; 95\% CI, 1.20-3.19). Of the patients who acquired melioidosis in the Darwin urban area, the proportion who were Indigenous Australians increased from $38 \%$ in $1989-2009$ to $53 \%$ in 2009-2010 (OR, 1.82; 95\% CI, 0.99 3.35). Of the 49 Indigenous Australian patients who acquired melioidosis in
2009-2010, 63\% were in the Darwin urban area; this compares with $35 \%$ of all Indigenous patients with melioidosis in the previous 20 years (OR, 3.17 ; $95 \%$ CI, 1.62-6.24). Among nonIndigenous patients, there was no significant change, with 28 of $42(67 \%)$ in 2009-2010 and 163 of $259(63 \%)$ in 1989-2009 acquiring melioidosis in the Darwin urban area.

The population-based annual incidence of melioidosis in the Top End in 2009-2010 was 50.2 cases per 100000 , compared with a prior mean annual incidence of 19.6 per $100000 .{ }^{9}$ The annual incidence of melioidosis in the Top End Indigenous population in 2009-2010 was 102.4 cases per 100000.

Box 5 shows some clinical examples of melioidosis. No patient without a recognised risk factor for melioidosis died from the disease during 20092010; 10 of the 11 patients who died had either diabetes or hazardous alcohol intake or both. Of the seven Indigenous patients who died from melioidosis in 2009-2010, five were initially from remote Indigenous communities but were living in the Darwin urban area when they acquired melioidosis (four of these were homeless); all five had hazardous alcohol intake. Eleven other Indigenous patients living in urban Darwin at diagnosis were originally from remote NT Indigenous communities. Over half had moved to Darwin within the preceding year. Nine of these 11 patients had hazardous alcohol intake as a risk factor, including three who were homeless.

Box 6 shows the monthly Top End cases of melioidosis for 2009-2010 in comparison to rainfall recorded at Darwin airport. In the Darwin urban area, there was substantially above average rainfall in December 2009 and January 2010. ${ }^{10}$ Total Darwin rainfall for the period 1 October 2009 to 30 September 2010 was $2122.4 \mathrm{~mm}$, compared with the mean yearly rainfall of $1712.7 \mathrm{~mm}$.

\section{Discussion}

The year beginning with the wet season of 2009-2010 had the highest recorded number of cases of melioidosis in the Top End for the past 21 years. Over these 12 months, our estimated population-based annual incidence of 50.2 cases per 100000 is the highest recorded anywhere in the melioidosis-endemic region of South-East Asia and northern Australia. The previous highest annual incidence in the Top End was 41.7 cases per 100000 population in the calendar year of 1998, which included case clusters following Tropical Cyclone Les, which flooded the town of Katherine, and Tropical Cyclone Thelma, which passed over the north-west end of the Tiwi Islands. ${ }^{9}$ The prior highest recorded annual incidence anywhere 
4 Clinical presentation and outcomes for patients with melioidosis managed at Royal Darwin Hospital from 1 October 1989 to 30 September 2010

\begin{tabular}{lccc} 
Clinical presentation & $1989-2009$ & 2009-2010 & $P$ \\
\hline Total patients & 540 & 91 & \\
Pneumonia & $278(51 \%)$ & $47(52 \%)$ & 1.00 \\
Bacteraemia, no focus & $59(11 \%)$ & $14(15 \%)$ & 0.29 \\
Skin ulcer or abscess & $68(13 \%)$ & $10(11 \%)$ & 0.80 \\
Genitourinary & $76(14 \%)$ & $8(9 \%)$ & 0.29 \\
Soft tissue abscess & $19(4 \%)$ & $5(5 \%)$ & 0.54 \\
Osteomyelitis/ & $20(4 \%)$ & $3(3 \%)$ & 1.00 \\
septic arthritis & $14(3 \%)$ & $1(1 \%)$ & 0.62 \\
Neurological melioidosis & $6(1 \%)$ & $3(3 \%) *$ & 0.25 \\
Other & & & \\
Severity and outcomes & $298(55 \%)$ & $57(63 \%)$ & 0.23 \\
Bacteraemia & $61(20 \%)$ & $10(18 \%)$ & 0.75 \\
$\quad$ Deaths & $116(21 \%)$ & $19(21 \%)$ & 1.00 \\
\hline Septic shock & $58(50 \%)$ & $9(47 \%)$ & 1.00 \\
\hline $\begin{array}{l}\text { Deaths } \\
\text { Ventilated in intensive care }\end{array}$ & $97(18 \%)$ & $16(18 \%)$ & 1.00 \\
\hline $\begin{array}{l}\text { Deaths } \\
\text { Total deaths }\end{array}$ & $41(42 \%)$ & $9(56 \%)$ & 0.44 \\
\hline * Others in 2009-2010 were ascitic fluid culture-positive melioidosis, liver \\
abscess, mediastinal lymphadenopathy/abscess.
\end{tabular}

\section{Clinical presentations of melioidosis during 2009-2010}

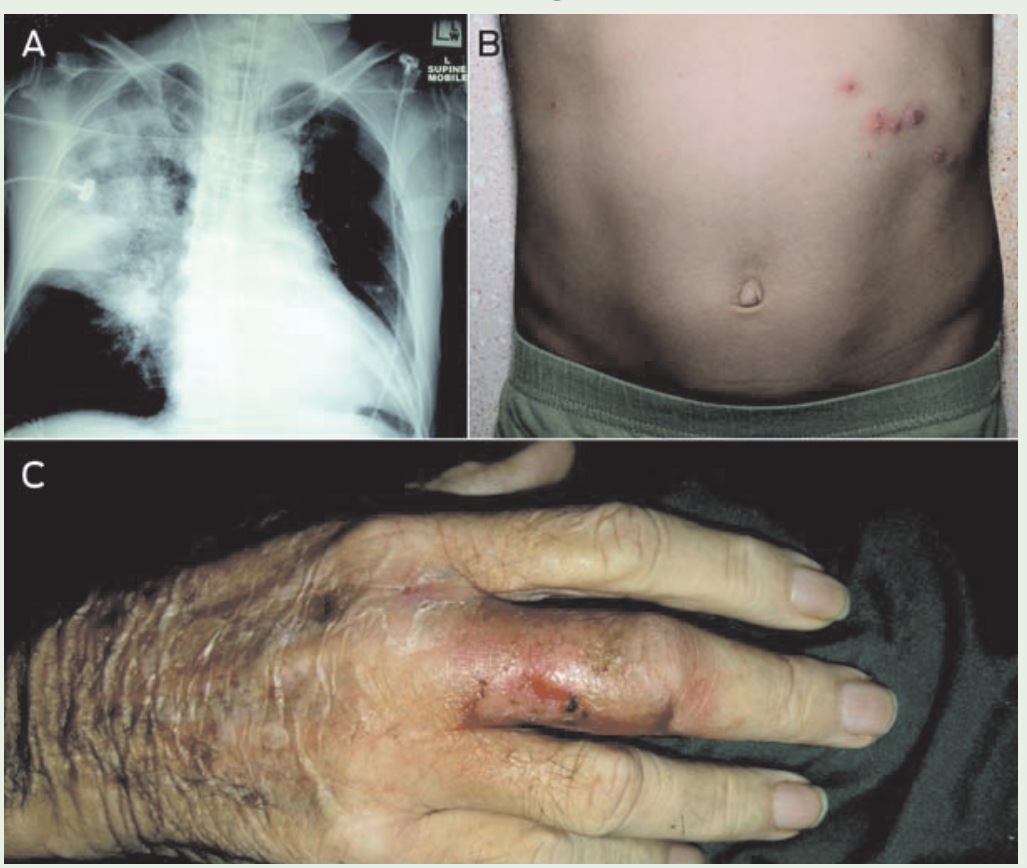

A: Chest $x$-ray of a 66-year-old man from Darwin with chronic lung disease, diabetes and ischaemic heart disease; his was the first death from melioidosis of the wet season, December 2009. B: A 4-year-old boy from Darwin with cutaneous melioidosis; possibly the result of an inoculating event in his muddy backyard. C: A 66-year-old person from Darwin with diabetes, osteomyelitis and a soft tissue abscess of right middle finger. else was 42.7 per 100000 in the Torres Strait Islands during 1995-2000. ${ }^{11}$

The association between melioidosis and rainfall and severe weather events is well recognised in Australia ${ }^{3,5,6}$ and South-East Asia. ${ }^{12,13}$ The 2009-2010 rainfall pattern is considered the major contributor to the increase in cases. There was consistently heavy rainfall in the Darwin area in December 2009 and January 2010, with two severe weather events leading to intense rainfall in December and February. Other Top End locations had variable rainfall patterns which were generally less intense than in Darwin.

In 2009-2010, the incidence of melioidosis of 102.4 cases per 100000 for Indigenous Australians was three times higher than that for non-Indigenous Australians. Even though the overall proportion of Indigenous cases remained the same, there was a significant reversal of the previous predominance of infected Indigenous patients being from remote communities to most being from urban Darwin in 2009-2010. The proportion of urban Darwin cases that was Indigenous increased from $38 \%$ to $53 \%$. That four out of five of the Indigenous people from Darwin who died from melioidosis in 2009-2010 were homeless, previously from remote communities and with excessive alcohol intake as their major risk factor, supports concerns that the Northern Territory Emergency Response initiated in 2007 may have had possible unintended consequences resulting from displacement of drinkers from remote communities to urban centres such as Darwin, where alcohol is available. ${ }^{14-16}$

In conclusion, the dramatic increase in the number of cases of melioidosis in the Top End in 20092010 represented an estimated population-based annual incidence that is the highest on record. One in every 1000 Indigenous people living in the Top End had culture-confirmed

\section{Correlation between cases of melioidosis managed at Royal Darwin Hospital in} 2009-2010 and rainfall at Darwin airport

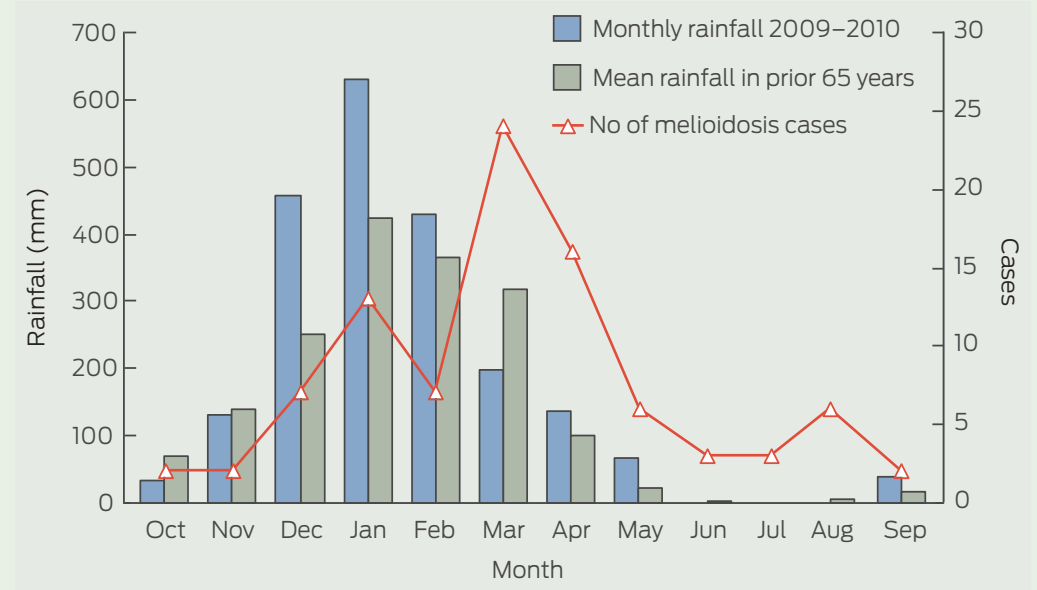


melioidosis over that 12-month period. The increase in cases was most prominent in the Darwin urban area, and was associated with increased rainfall. There was also an increased proportion of Indigenous Australians who acquired melioidosis in Darwin compared with the preceding 20 years, which may reflect movement of some Indigenous people into Darwin from remote communities.

Acknowledgements: We thank our colleagues in the RDH infectious diseases and microbiology departments and intensive care unit, and from the NT Centre for Disease Control, for their expertise and assistance with diagnosing and managing the patients with melioidosis. This study is supported by grants from the Australian National Health and Medical Research Council (Project Grant 605820) and the United States National Institutes of Health (UOI A1075568-01).

Competing interests: No relevant disclosures. Received 10 Sep 2011, accepted 19 Dec 2011.

1 Cottew GS, Sutherland AK, Meehan JF. Melioidosis in sheep in Queensland: description of an outbreak. Aust Vet J 1952; 5: 113-123.
2 Crotty JM, Bromich AF, Quinn JV, Brotherton J. Melioidosis in the Northern Territory: a report of two cases. Med J Aust 1963; 50: 274-275.

3 Cheng AC, Currie BJ. Melioidosis: epidemiology, pathophysiology, and management. Clin Microbiol Rev 2005; 18: 383-416.

4 Malczewski AB, Oman KM, Norton RE, Ketheesan N. Clinical presentation of melioidosis in Queensland, Australia. Trans R Soc Trop Med Hyg 2005; 99: 856860.

5 Hanna JN, Humphreys JL, Brookes DL, et al. Melioidosis in north Queensland, 2000-2009. Commun Dis Intell 2010; 34: 444-447.

6 CurrieBJ, Ward L. Cheng AC. The epidemiology and clinical spectrum of melioidosis: 540 cases from the 20 year Darwin prospective study. PLoS Negl Trop Dis 2010; 4: e900.

7 Currie BJ, Fisher DA, Howard DM, et al. Endemic melioidosis in tropical northern Australia: a 10-year prospective study and review of the literature. Clin Infect Dis 2000; 31: 981-986.

8 Health Gains Planning Department. Northern Territory resident population estimates by age, sex, indigenous status and health districts (1971-2010). Darwin: Northern Territory Department of Health, 2011.

9 Currie BJ, Jacups SP, Cheng AC, et al. Melioidosis epidemiology and risk factors from a prospective whole-population study in northern Australia. Trop Med Int Health 2004; 9: 1167-1174.
10 Australian Government Bureau of Meteorology. Monthly weather review Northern Territory December 2009. Canberra: Commonwealth of Australia, 2010. http://www.bom.gov.au/climate/ mwr/nt/mwr-nt-200912.pdf (accessed Dec 2011).

11 Faa AG, HoltPJ. Melioidosis in the Torres Strait Islands of Far North Queensland. Commun Dis Intell 2002; 26: $279-283$.

12 Suputtamongkol Y, Hall AJ, Dance DA, et al. The epidemiology of melioidosis in Ubon Ratchatani, northeast Thailand. Int J Epidemiol 1994; 23: 10821090.

13 Lo TJ, Ang LW, James L, Goh KT. Melioidosis in a tropical city state, Singapore. Emerg Infect Dis 2009 15: 1645-1647.

14 d'Abbs PHN. Alcohol restrictions in Indigenous communities: necessary but not sufficient [comment]. Med J Aust 2011; 194: 507.

15 Australian Government Attorney-General's Department. Report of the Northern Territory Emergency Response Review Board. Canberra: Commonwealth of Australia, 2008. http:// www.nterreview.gov.au/docs/report nter_review/ ch2.htm\#2_2 (accessed Dec 2011).

16 Australian Indigenous Doctors' Association; Centre for Health Equity Training, Research and Evaluation, UNSW. Health impact assessment of the Northern Territory Emergency Response. Canberra: AIDA, 2010. http://www.aida.org.au/hia.aspx (accessed Dec 2011). 